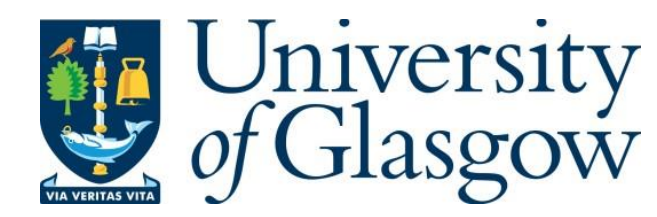

Charlton, J., Albanese, A. and Brodie, L. (2018) The challenges of type 1 diabetes and new psychoactive substance misuse. Practical Diabetes, 35(3), 81-85a.

There may be differences between this version and the published version. You are advised to consult the publisher's version if you wish to cite from it.

This is the peer reviewed version of the following article Charlton, J., Albanese, A. and Brodie, L. (2018) The challenges of type 1 diabetes and new psychoactive substance misuse. Practical Diabetes, 35(3), 81-85a.

http://dx.doi.org/10.1002/pdi.2168

This article may be used for non-commercial purposes in accordance with Wiley Terms and Conditions for Self-Archiving.

http://eprints.gla.ac.uk/163249/

Deposited on: 1 June 2018

Enlighten - Research publications by members of the University of Glasgow http://eprints.gla.ac.uk 


\title{
The Challenges of Type 1 Diabetes and New Psychoactive Substance Misuse
}

\section{Jacqui Charlton, Alessio Albanese, Liz Brodie}

\begin{abstract}
:
Aim: Substance misuse, specifically novel psychoactive substances (NPSs), can have multiple effects on physical and psychological health and well-being. This is of particular concern to people with Type 1 Diabetes (T1DM) as their use may impact on effective glucose management and may result in acute complications and deleterious consequences. This review aims to investigate the physical and psychological effects of NPSs and traditional illicit drug use on glycaemic control and corresponding self-care for people with T1DM.
\end{abstract}

Method: We performed a literature search of seven electronic databases for articles published between 2011-2017, using MeSH search headings: diabetes, young people, substance misuse, novel psychoactive substances, club drugs, street drugs, rave drugs, legal highs, designer drugs, research chemicals, glycaemic control, ketoacidosis, self-management, and harm reduction.

Results: Literature was scant, despite the available evidence of increased substance use in the UK. There is a paucity of evidence about the effects of NPSs and traditional illicit drug use on glycaemic control, and a lack of educational information which could be used to inform users with T1DM and HCPs about their risks and preventative self-care strategies.

Conclusion: Patient awareness of potential problems with regard to safety is an essential component of effective risk management, health protection and glycaemic control. HCPs also 
require evidence based information regarding these components in order to communicate and empower patients who choose to participate in this potential risky behaviour.

Key words: Diabetes, young people, substance misuse, glycaemic control, ketoacidosis, selfmanagement, harm reduction.

\section{Key points:}

1. NPSs have caused a change in pattern of recreational drug use. An increasingly common trend is poly-drug use which includes alcohol consumption.

2. It is unlikely that illicit drug users with T1DM would volunteer information if they are not introduced into the dialogue by the HCP.

3. Diabetes care teams should be mindful that illicit drug use may be common in adolescents with T1DM, with the most popular being cannabis (and NPS equivalent), ecstacy, cocaine, speed and mephedrone (NPS).

4. The main risks of illicit drug use appear to be hyperglycaemia, and DKA can be precipitated by ketosis caused by stimulant-enhanced lipolysis from sympathetic overactivity.

5. Illicit drugs along with the cognitive impact of substance intoxication on decision making for self-care, plus predisposing poor glycaemic control, can result in DKA.

6. Similarities between the symptoms of hypo and hyperglycaemia and the effects of NPSs and illicit drugs could obscure the identification of a glucose problem, and the only method of identifying the cause of the effect/symptom is by blood glucose testing. 


\section{$\underline{\text { Introduction }}$}

New psychoactive substances (NPSs) which first emerged around 40 years ago, are also described as club drugs, designer drugs or research chemicals. These were misleadingly known as 'legal highs' due to their initial exclusion from existing drugs legislation ${ }^{1}$ within the UK. This enabled easy availability from high street shops and multiple online sources ${ }^{2}$, which appealed to young people as the dark net was less favourable to younger NPS users ${ }^{3}$.

NPSs are synthetic compounds sought for their intoxicant effects and perceived lower risk and cost than their traditional illicit drug equivalents, and have caused a change in patterns of recreational drug use away from more traditional substances. Their colloquial names such as bath salts, spice, and plant foods also enhance the idea of reduced risk. However recently, legislation in the UK ${ }^{4}$ has categorised NPSs alongside their illicit counterparts such as cannabinoids, opioids and stimulants.

There is evidence to suggest that school students are increasingly attracted to NPSs through information gained from peers, social media and other online sources ${ }^{5}$. However, only five per cent of 15-year olds report using one or more NPSs, which is lower compared to $17 \%$ using cannabis, and comparable to five percent of ecstasy or four percent of cocaine users ${ }^{6}$. Interestingly, the five percent of NPSs users report consuming synthetic cannabis (72\%), and mephedrone (71\%), which mimic ecstasy and cocaine. In England and Wales, 20\% of 16-24 year olds and $15 \%$ of $11-15$ year olds have used an illicit drug in the last year. From these, $9 \%$ and $5 \%$ have used cannabis respectively ${ }^{7}$. Measham and colleagues ${ }^{8}$ suggests that NPSs are now frequently used to supplement rather than replace more traditional illicit drugs, thus exacerbating the acute effects and the risks to health for users ${ }^{5}$. In 2015 drug misuse in England 
and wales accounted for nearly 1 in 8 deaths among people in their 20 s and 30s, however highest rates of drug misuse deaths are currently are among people in their 30s and 40s.

There is also an increasing trend of poly-drug use which refers to the use of more than one drug taken at the same time or sequentially by an individual ${ }^{9}$. This pattern also includes alcohol consumption ${ }^{10,11}$.

Due to the large, and increasing number of NPSs that are available ${ }^{12,13}$, and with resulting changes in recreational drug-use patterns including regional variations, difficulty arises for HCPs to conduct assessments and plan care. These present challenges to HCPs and users alike, with the additional complication resulting from the fact that T1DM can exacerbate further.

\section{Vulnerability of young people with T1DM and NPS use}

In the UK, there are approximately 400,000 people with $\mathrm{T} 1 \mathrm{DM}{ }^{14}$. For a young person with T1DM, maintaining acceptable glucose control whilst participating in lifestyle activities with peers can prove challenging. Difficulties may arise when experiencing new situations such as initiation to alcohol consumption, sexual activity, leaving home, diminishing parental supervision, starting higher education courses and employment, and meeting new friends ${ }^{15}$. Realistically, diabetes management may not necessarily be a priority during this period in their lives. These activities and related social environments such as bars/clubs, music festivals and student social spaces can increase the exposure to illicit drug use. It is also suggested that young people with chronic conditions may be at greater risk of engaging in high risk behaviours compared to their healthy peers ${ }^{16}$. In addition, other factors such as homelessness, early life trauma, pre-existing mental health problems and sexuality, can influence both the initiation into drug use and high-risk behaviors ${ }^{17}$. 


\section{The prevalence of illicit drug use.}

Prevalence of use within our clinic populations is important to understand in order to gauge the extent of risk amongst young people. In 2012, Lee and colleagues ${ }^{18}$ showed that recreational drug use was most commonly reported among respondents under the age of 20 , and least commonly among respondents aged 25 to 29 years. $\mathrm{Ng}$ et al. ${ }^{19}$ indicated that $29 \%$ of 85 study participants aged between 16 and 30 years reported using street drugs. Of those, $68 \%$ habitually took street drugs more than once a month, $72 \%$ of whom were unaware of the adverse effects of drug taking on the management of T1DM. Snyder et al. ${ }^{10}$ questioned 60 adolescents with T1DM aged between 12 and 20 years about their use of alcohol and tobacco alongside illicit substances. This study reported that the prevalence of substance use was $36.7 \%$ among participants. Of these, older participants and those with depression were more likely to engage in illicit substance use.

With regard to glycaemic control, Snyder et al. ${ }^{10}$ suggested that illicit drug use was not correlated to glycaemic control or diabetes self-management. Whereas Lee et al. ${ }^{18}$, showed that poor glycaemic control was up to three times more common among drug users compared with non-users. In this group, drug use was associated with poor glycaemic control, independent of age, gender, duration of diabetes and tobacco smoking. $\mathrm{Ng}$ et al. ${ }^{19}$ confirmed that DKA and poor glycaemic control in young adults with T1DM may be caused by 'street drug' use. These results were echoed by Wong and Holt ${ }^{20}$ who also concluded that HCPs should recognise that street-drug use, including NPSs, may be associated with poor glycaemic control and increased risk of DKA. While acknowledging that the results are derived from older studies, these data 
suggest that diabetes care teams should be mindful that illicit drug use are common in adolescents with T1DM.

\section{Diabetes HCP and patient interaction}

It is apparent that the use of illicit drugs by young adults is not deterred by having the diagnosis of T1DM ${ }^{10,19}$ which can present several challenges for both the young person and the diabetes HCP. Lee et al ${ }^{18}$ indicated that from a survey of 388 T1DM respondents, only $7 \%$ informed HCPs about their illicit drug use and that it was unlikely for users to volunteer information about substance use unless they were introduced into the dialogue by the HCP.

Hence, one crucial element in a consultation is how to approach the subject. However, it is understood that the unlawful use of substances along with confidentiality issues may hinder the initial opening of conversation. From an HCP perspective, considerations around patient interaction, communication and engagement are important, as is open dialogue. However, once discussions start, the HCP has potentially limited awareness of the use, knowledge, risks, and evidence to provide education and support ${ }^{20,11}$. This can result in a lack of confidence in how to respond to a disclosure of illicit drug use which may lead to avoidance of further discussion around NPSs or other substances. As Lee et al. ${ }^{11}$ suggested, the lack of understanding of the effects of substance properties makes patient advice and education difficult. For NPSs, the unknown composition of the psychoactive agent adds to the challenges not only to users who rely on sellers' descriptions ${ }^{21}$ but also to HCPs, which limits their ability to provide topical advice on risks and harms associated with NPS use. For clinical practice, existing knowledge around the effects of traditional illicit drugs with similar NPS groupings should be used for the possible impact on glycaemic control (see table 1). The lack of patient information both in 
leaflet form and digital resources may result in the subject being overlooked during consultations.

\section{The effects on glucose control}

Existing literature reports high mortality from acute diabetes-related events associated with substance misuse $^{22}$. In relation to blood glucose management, the main risks of illicit drug use (excluding NPSs as no literature was found) appear to be hyperglycaemia and life-threatening diabetic ketoacidosis (DKA). The most commonly used substances are cannabis (and NPS equivalent), ecstacy, cocaine, speed and mephedrone (NPS). In 2008, Lee et al ${ }^{23}$ reported on 19 patients with T1DM who presented with DKA during a 10-month period. Of these, 10 patients reported illicit drug use in the 48 hour period before presentation, including cannabis $(n=8)$, ecstasy $(n=6)$, ketamine $(n=6)$, benzodiazepines $(n=3)$ and heroin $(n=3)$, with seven patients being poly-drug users. Within this study there was no reference to NPS usage, which may be because in 2008 the awareness and availability of NPSs was not to the extent that it is now. However, with regard to illicit drug use, resources are limited for people with T1DM to highlight associated risks in relation to blood glucose levels, and important preventative selfcare strategies. This is somewhat understandable as original research is rare, possibly due to researcher unawareness of the problem, or difficulties obtaining ethical approval due to legalities of investigating illicit substances and potential glycaemic consequences. In comparison to illicit drug use, alcohol, which is a licit substance, is known predominantly for hypoglycaemic risks and to a lesser extent potential hyperglycaemia. It is known that there are some safe-drinking guidelines available which focus around safe consumption and include selfcare strategies including carbohydrate consumption, possible insulin adjusting, and the benefits of blood glucose testing. Poly-drug use guidelines combining alcohol and illicit drug use are now required. 
The current upsurge in availability of NPSs over the last decade has led to an emerging body of literature about NPSs and their effects on young people. However, there is an absence of evidence demonstrating the clinical effects of NPS use and impact on people with T1DM. The list of effects and resultant clinical risk is challenging to summarise due to the variety of available substances and their frequently changing chemical composition. Nonetheless, Table 2 attempts to provide an overview of the effects and clinical impact of the most commonly encountered NPSs along with their illicit drug counterparts.

\section{Specific drug types and effects}

As described previously, of most concern to young people regarding NPSs, are synthetic cannabinoids and mephedrone, which primarily has a stimulating effect and has been widely used since $2009^{24}$, with highest use occurring in those under 21 years of age. Despite common and frequently used drugs within the cannabinoid group, no evidence is reported regarding T1DM. However, given that a common effect of cannabis is increased appetite, one can speculate that this can lead to hyperglycaemia unless self-care regarding insulin administration is carried out.

With regard to mephedrone, the perceived positive effects such as euphoria, overall disinhibition, along with the sense of energy experienced with this stimulant drug ${ }^{25,26}$ can also have a negative impact on health, and could greatly influence attention to diabetes self-care. Wong and Holt ${ }^{20}$ reported a case study which focused on an 18-year-old male with T1DM, who was admitted with DKA following mephedrone use. The patient was a regular user, and on admission was unable to remember insulin administration or food consumption. In this instance, mephedrone impaired individual awareness and ability to self-manage their diabetes. 
In addition, there is some evidence to support the physiological effect of other illicit drugs with stimulant properties such as MDMA (ecstasy), amphetamine (speed), and cocaine which can cause dehydration and DKA ${ }^{20}$. It is already recognised that MDMA requires increased insulin doses ${ }^{18}$, and interestingly despite the lack of knowledge related to self-management, respondents reported an increase in insulin dose intake by $100-150$ percent in an attempt to reduce hyperglycaemia. Lee and colleagues ${ }^{23}$ also explained that hyperglycaemic properties of cannabis, heroin and ecstacy can precipitate DKA by ketosis-caused, stimulant-enhanced lipolysis from sympathetic over-activity. Ketamine can also cause severe acidosis. These drugs along with a predisposition to poor glycaemic control and inadequate insulin administration ${ }^{20}$, can result in DKA. Lee et al. ${ }^{23}$ indicate that people at risk have poor glycaemic control due to insulin underutilization, which also was shown by Lee et al. ${ }^{18}$ and $\mathrm{Ng}$ et al ${ }^{19}$.

\section{Challenges and impact on glycaemic control.}

Similarities between the symptoms of hypo and hyperglycaemia and the effects of NPSs and illicit drugs, complicate the clinical picture for both patients and HCPs, which is shown in tables 1 and 2. This could obscure the identification of a glucose problem and unfortunately the only method of identifying the cause of the effect/symptom is by blood glucose testing, which is often ignored by this patient group ${ }^{18}$. The cognitive impact of substance intoxication on decision making for self-care is also under-recognized, especially with the influence on insulin compliance. It is also known that poor glycaemic control can be associated with chaotic lifestyles, denial of chronic disease management, and poor social support ${ }^{27}$. These factors can increase the risk of depression in people with diabetes which in turn, can exacerbate drug use 10. 
Reassuringly, $\mathrm{Ng}$ et al. ${ }^{19}$ reported that $28 \%$ of their study cohort were aware of the adverse effects on diabetes management when partaking in illicit drug use, and interestingly $48 \%$ inform friends about having diabetes and perform blood glucose monitoring. From a patient perspective a clinical emergency tends to be perceived as hypoglycaemia rather than hyperglycaemia, thus the risks of ketoacidosis may be overlooked. The stimulant drugs causing frenetic behaviour and increased activity such as cocaine, MDMA and mephedrone could cause fear of hypoglycaemia due to the glucose lowering effects of increased activity. Also, some situations may cause the user to be concerned about recognising or treating dangerously low glucose levels. Examples of which are epitomised by opioids, cannabinoids, empathogens and dissociatives. This may encourage preventative hypoglycaemic self-care strategies which would be insulin reduction or omission, or increased $\mathrm{CHO}$ consumption. For a user with T1DM, in order to understand self-care strategies the basic physiological effects of insulin and glucagon must be understood. Increased activity requiring increased blood glucose for cellular energy will result in glycogenosis. If exogenous insulin is not administered, hyperglycaemia and DKA can occur. This is a difficult concept and situation for the patient and HCP to discuss and understand without individual glucose monitoring to reveal the effect of the drug and inform appropriate and safe insulin administration.

In view of this, it should be noted that the wide-ranging health implications of all substances are not simply due to the pharmacology of the drug, but they are greatly influenced by lifestyle, which can have an impact on diabetes. Particular concerns are related to dietary neglect, lack of self-care and lack of medication adherence.

\section{Alcohol and poly-drug use}


Alcohol is now frequently used as part of a poly-drug culture and is particularly used in binges associated with NPSs, and most commonly associated with mephedrone, which increases disinhibition and high-risk behaviour ${ }^{25}$. Alcohol is a depressant, and its effects and risks on glucose control in T1DM are recognized, but self-care advice is limited ${ }^{28}$. The effect of alcohol on glycaemia depends on the type of beverage and amount consumed ${ }^{29}$. In relation to polydrug practice, beverages such as cider and alcopops will cause hyperglycaemia, whereas beer, wine and spirits can cause hypoglycaemia and glucose variability.

Regarding these patterns associated with substance use, a lack of understanding is common ${ }^{30}$. This adds to the severe acute complication risk when combined with illicit substances. Ecstasy used alongside alcohol, can impair thermal regulation and increase dehydration, and lead to sympathetic hyperactivity that may result in impaired cardiac functioning ${ }^{31,32}$.

\section{Cognitive effects in relation to self-care and blood glucose management}

Current findings suggest a shortage of self-care strategies to ensure safety and risk reduction for potential severe complications, especially DKA ${ }^{11}$. It is therefore not surprising that users are oblivious to the danger of effects from both the substance and diabetes management, especially regarding insulin administration ${ }^{19}$. The effects of drugs and their impact on hypo and hyperglycaemic symptoms without blood glucose testing could be misunderstood and cause inappropriate insulin administration as described by Lee et al. ${ }^{18}$, where it was demonstrated that MDMA users self-administer up to more than double the usual insulin dose. However, there are limited resources available for people with T1DM regarding illicit drug use, associated risks in relation to blood glucose levels, and related preventative self-care strategies. Due to the multiple variables associated with young people and substance use, recommendations are difficult to collate ${ }^{11}$. Until specific evidence based guidelines are 
available, HCPs should be aware of existing harm reduction advice which is advocated for all users of NPSs and illicit drugs (see table 3).

\section{Conclusion}

In summary, this review confirms that for a person with T1DM using illicit drugs presents a risk of hyperglycaemia and DKA. The drug effects may also obscure the recognition of hyperglycaemia or hypoglycaemia, and compromise self-care awareness and behaviour. In view of this we should be targeting the at-risk population with a specific detection and prevention strategy, which could be included in HCP review appointments leading onto the discussion of self-care strategies. This review has highlighted the dearth of evidence regarding an effective intervention, and the need for the development of educational resources for users with T1DM and HCPs to prevent potentially lethal consequences. For HCPs to effectively support and educate people with T1DM who use substances, they must know the effects of different drug groups on glycaemic control and self-care strategies which can prevent complications and fatalities of this under-reported health risk. Regional variations in drug-taking behaviours would indicate a flexible/bespoke approach may be required. With the recent legislation on Flash glucose monitoring on NHS prescriptions becoming available this may help HCPs and illicit drug-users understand the impact on glucose control.

Acknowledgement: Thanks to Mark Adley for his kind permission to use the Drugs Wheel. 
Table 1: The Drugs Wheel: a new model for substance awareness. Developed in

collaboration with DrugWatch and reproduced in its entirety from: www.thedrugswheel.com (copyright CC-BY-NC-SA 4.0).

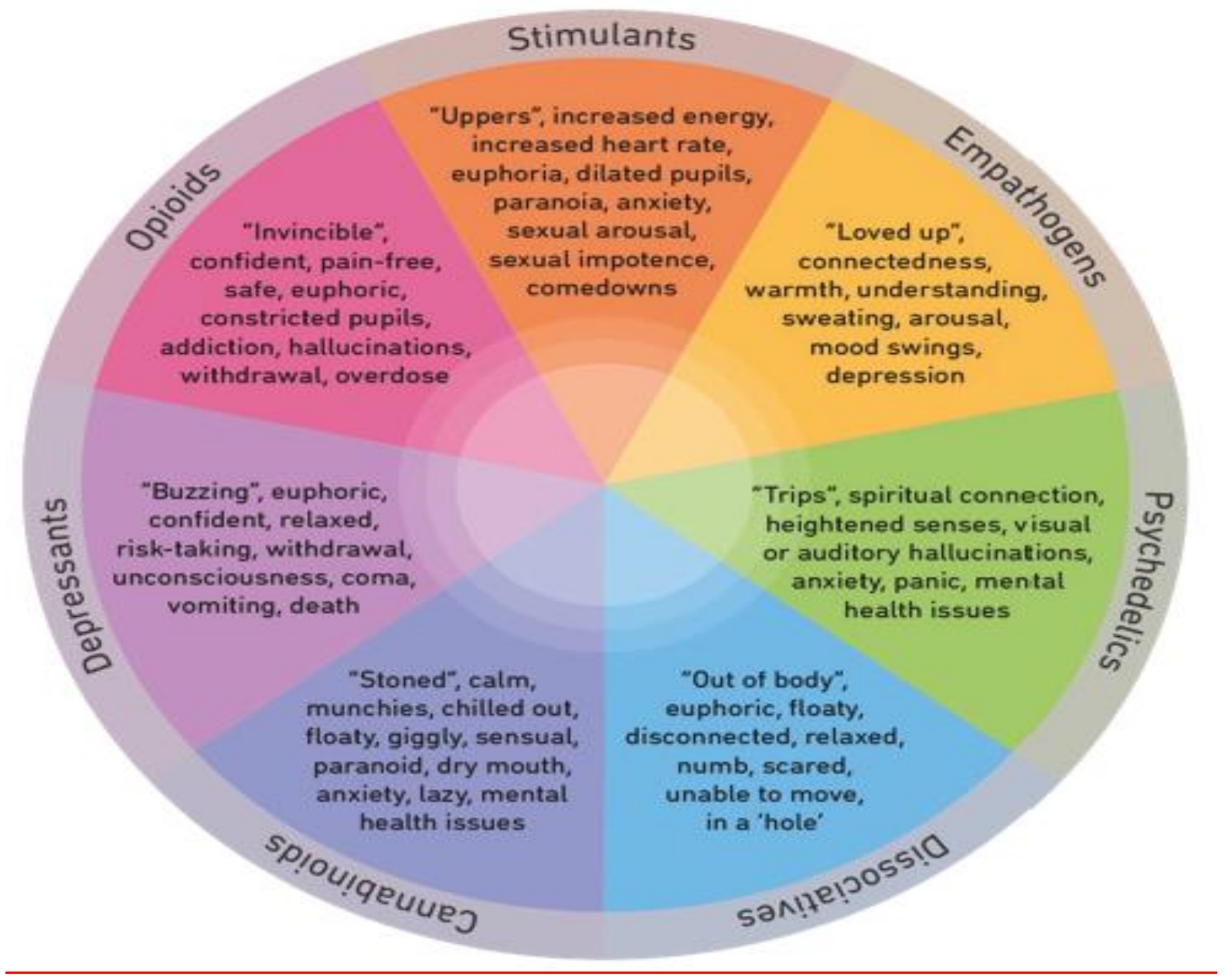


Table 2: Illicit drug and equivalent NPS, effects and potential glycaemic risks

\begin{tabular}{|c|c|c|c|}
\hline Drug group & Example & Effects & $\begin{array}{l}\text { Effects similar to } \\
\text { hypo/hyperglycaemia and/or } \\
\text { risks for hypo/hyperglycaemia }\end{array}$ \\
\hline Stimulants & $\begin{array}{l}\text { Cocaine, Ecstacy } \\
\text { (MDMA), } \\
\text { Amphetamine, } \\
\text { Mephedrone. } \\
\end{array}$ & $\begin{array}{l}\text { Euphoria, relief from } \\
\text { fatigue, increased } \\
\text { activity levels, sense of } \\
\text { well-being, confidence. }\end{array}$ & $\begin{array}{l}\text { Mood swings, visual and auditory } \\
\text { hallucinations, sweating, nausea, } \\
\text { dehydration, lowered appetite. }\end{array}$ \\
\hline Opioids & $\begin{array}{l}\text { Heroin, } \\
\text { Methadone, } \\
\text { Dihydrocodeine } \\
\text { Fentanyl } \\
\text { Kratom } \\
\end{array}$ & $\begin{array}{l}\text { Euphoria, feelings of } \\
\text { safety and warmth, sense } \\
\text { of well-being, } \\
\text { confidence. }\end{array}$ & Sweating, drowsy. \\
\hline $\begin{array}{l}\text { Hallucinogens } \\
\text { and } \\
\text { psychedelic } \\
\text { drugs }\end{array}$ & LSD, Psilocybin & $\begin{array}{l}\text { Euphoria, heightened } \\
\text { sensory awareness, } \\
\text { connectedness, } \\
\text { hallucinations }\end{array}$ & Psychosis, anxiety \\
\hline $\begin{array}{l}\text { Dissociative } \\
\text { drugs }\end{array}$ & $\begin{array}{l}\text { Ketamine, Salvia, } \\
\text { Nitrous Oxide }\end{array}$ & $\begin{array}{l}\text { Out of body, calm } \\
\text { relaxed, numb, unable to } \\
\text { move, can distort } \\
\text { perceptions of sight and } \\
\text { sound and create } \\
\text { feelings of detachment } \\
\text { or dissociation from the } \\
\text { self and the } \\
\text { environment. }\end{array}$ & $\begin{array}{l}\text { Ketamine can precipitate DKA in } \\
\text { T1DM. The metabolic acidosis } \\
\text { can be severe. }\end{array}$ \\
\hline Empathogens & MDMA & $\begin{array}{l}\text { Warm, mellow, sense of } \\
\text { belonging, depression }\end{array}$ & Sweating, mood swings. \\
\hline Cannabinoids & $\begin{array}{l}\text { Cannabis, } \\
\text { Synthetic cannabis }\end{array}$ & $\begin{array}{l}\text { Calm, relaxed, excited, } \\
\text { giggling, energetic. }\end{array}$ & $\begin{array}{l}\text { Dry mouth, increased appetite, } \\
\text { loss of memory. }\end{array}$ \\
\hline Depressants & $\begin{array}{l}\text { Diazepam, } \\
\text { Etizolam, } \\
\text { Temazepan, } \\
\text { Gabapentin, Kava, } \\
\text { Solvents. }\end{array}$ & Relaxed, disinhibition. & \\
\hline
\end{tabular}

N.B: NPSs highlighted in red, possible causes of hyper/hypoglycaemia highlighted in blue. 
Table 3: Current advice regarding general harm reduction and diabetes management Current advise for people with T1DM (Hicks 2017)

Advice should be given to maintain safety prior, during and after taking drugs or alcohol, including the following:

- Carry identification stating that the user has diabetes and requires medication.

- Check blood glucose levels before using, and after "coming down".

- If low, have some food, and drink sugary drinks in between water, especially if there is no appetite.

- Drink plenty of water.

- Eat a meal containing carbohydrate as soon as possible after coming down.

Harm reduction (adapted from Crew2000 2016)

- Know your substance and try to buy from familiar sources, and avoid injection.

- Avoid using alone, and tell people what you have taken.

- Avoid mixing different drugs and alcohol, and wait at least an hour before redosing.

- Take regular breaks when dancing, and keep hydrated.

- Seek immediate help if you start to feel unwell. 


\section{References}

1. Misuse of Drugs Act. http://www.legislation.gov.uk/ukpga/1971/38\#pb4-11g8 [Retrieved 10-10-2017].

2. Barratt, M., Ferris, J., \& Winstock, A. Use of Silk Road, the online drug marketplace, in the United Kingdom, Australia and the United States. Addiction 2014; 109(5): 774-783.

3. Van Buskirk, J., Roxburgh, A., Bruno, R., Naicker, S., Lenton, S., Sutherland, R. Characterising dark net marketplace purchasers in a sample of regular psychostimulant users. The International Journal on Drug Policy 2016; 35: 32-7.

4. Psychoactive Substances Act. http://www.legislation.gov.uk/ukpga/2016/2/contents/enacted [Retrieved 13/12/2017]

5. Moore, K., Dargan, P.I., Wood, D. M., Maesham, F. Do novel psychoactive substances displace established club drugs, supplement them or act as drugs of initiation? The relationship between mephedrone, ecstasy and cocaine. European Addictions Research. 2013; 19(5): 276-82.

6. Scottish Schools Adolescent Lifestyle and Substance Use Survey (SALSUS) Drug Use Among 13 and 15 year olds in Scotland 2015 CNHS National Services Scotland/Crown Copyright 2015. 
7. National Treatment Agency for Substance Misuse, (2011): A summary of the health harms of drugs. DOH, London. http://www.nta.nhs.uk/uploads/healthharmsfinal-v1.pdf [Retrieved $13 / 12 / 2017]$

8. Maesham, F., Moore, K., Østergaard, J. Mephedrone, 'Bubble' and unidentified white powders: the contested identities of synthetic 'legal highs'. Drugs Alcohol Today. 2011; 11(3): $137-47$.

9. EMCDDA 2011 Annual report on the state of the drugs problem in the European Union and Norway. Luxembourg: Office for official publications of the European Community. http://www.emcdda.europa.eu/attachements.cfm/att_143743_EN_EMCDDA_AR2011_EN.p df [Retrieved 13/12/2017].

10. Snyder, L. L., Truong, Y. K. N., Law, J. R. Evaluating Substance Use and Insulin Misuse in Adolescents With Type 1 Diabetes. The Diabetes Educator 2016; 20 (10): 1-9.

11. Lee, P., Greenfield, J. R., Campbell, L. V.Managing young people with Type 1 diabetes in a 'rave' new world: metabolic complications of substance abuse in Type 1 diabetes. Diabetic Medicine 2009; 26: 328-333.

12. Davey, Z., Schifano, F., Corazza, O., De Luca, P. e-Psychonauts: Conducting research in online drugs forum communities. Journal of Mental Health. 2012; 21: 386-94.

13. De Luca M. A., Solinas M., Bimpisidis Z., Goldberg S. R., Di Chiara G. Cannabinoid facilitation of behavioural and biochemical hedonic taste responses. Neuropharmacology. 2012; 63: 161-168.

14. Juvenile Diabetes Research Foundation (2016) https://jdrf.org.uk/about-type-1-diabetes/ [Retrieved 26/9/2016]. 
15. Peters, A., \& Laffel, L. Diabetes Care for Emerging Adults: Recommendations for Transition From Pediatric to Adult Diabetes Care Systems. Diabetes Care. 2011; 34(11): $2477-2485$

16. Suris, J., \& Parera, N. Sex, drugs and chronic illness: Health behaviours among chronically ill youth. The European Journal of Public Health. 2005; 15(5): 484-488.

17. Carliner, Dunn, Keyes, \& Martins. Childhood trauma and initiation of drug use in adolescence. Drug and Alcohol Dependence. 2015; 156: E37.

18. Lee, P., Greenfield, J. R., Gilbert, K., Campbell L.V. Recreational drug use in type 1 diabetes: an invisible accomplice to poor glycaemic control? Internal Medicine Journal. 2012;198-202.

19. Ng, R. S. H., Darko, D. A., Hillson, R. M. Street drug use among patients with Type 1 diabetes in the UK. Diabetic Medicine. 2003; 21: 295-296.

20. Wong, M. L., Holt, R. I. G. The potential dangers of mephedrone in people with diabetes: a case report. Drug Testing and Analysis. 2011; 3: 464-465.

21. Jebadurai, J., Schifano, F., \& Deluca, P. Recreational use of 1-(2-naphthyl)-2-(1pyrrolidinyl)-1-pentanone hydrochloride (NRG-1), 6-(2-aminopropyl) benzofuran (Benzofury/ 6-APB) and NRG-2 with review of available evidence-based literature. Human Psychopharmacology: Clinical and Experimental. 2013; 28(4): 356-364. 
22. Laing S., P. Jones M., E. Swerdlow A., J., et al. Psychosocial and socioeconomic risk factors for premature death in young people with type 1 diabetes. Diabetes Care. 2005; 28: 1618-23.

23. Lee, P., Nicoll, A. J., McDonough, M., Colman, P. G. Substance abuse in young patients with type 1 diabetes: easily neglected in complex medical management. Internal Medicine Journal. 2005; 35(6): 359-61.

24. Winstock, A., Mitcheson, L., Ramsey, J., Davies, S., Puchnarewicz, M., \& Marsden, J. Mephedrone: use, subjective effects and health risks. Addiction. 2011; 106(11): 1991-1996.

25._Karila, L., Billieux, J., Benyamina, A., Lançon, C., \& Cottencin, O. The effects and risks associated to mephedrone and methylone in humans: A review of the preliminary evidences. Brain Research Bulletin. 2016; 126: 61-67.

26. Wood, \& Dargan. Mephedrone (4-methylmethcathinone): What is new in our understanding of its use and toxicity. Progress in Neuropsychopharmacology \& Biological Psychiatry. 2012; 39(2): 227-233.

27. Jones, M., Hepburn, S., Man, J., Ridout, J., \& Gable, D. A community outreach service for vulnerable people with diabetes. Diabetes and Primary Care. 2011; 13(2): 111.

28. Hirst, J. A., Aronson, J. K., Feakins, B. G., Ma, C., Farmer, A. J., Stevens, R. J. Shortand medium-term effects of light to moderate alcohol intake on glycaemic control in diabetes mellitus: a systematic review and meta-analysis of randomised trials. Diabetes Medicine. 2016; 35(5): 604-11. 
29. Ismail, D., Gebert, R., Vuillermin, P. J., Fraser, L., McDonnell, C. M., Donath, S. M., Cameron, F. J. Social Consumption of alcohol in adolescents with Type 1 diabetes is associated with increased glucose lability, but not hypoglycaemia. Diabetes Medicine. 2006; 23(8): 830-33.

30. Battistella, G., et al. Long-term effects of cannabis on brain structure. Neuropharmacology. 2014; 39(9): 2041-48.

31. DrugScope (2001): Drug abuse briefing: a guide to the non-medical use of drugs in Britain, eighth edition, DrugScope, London

32. Leccese, A. P., Pennings, E. J. M. and De Wolff, F. A. Combined use of alcohol and psychotropic drugs. A review of the literature, Academisch Ziekenhuis Leiden (AZL). 2000. 